\title{
Counselling needs and experience of junior hospital doctors
}

\author{
Paul Garrud
}

\begin{abstract}
A sample of 106 senior house officers who had graduated from Nottingham University in 1987 was surveyed about their experience of and need for careers guidance, peformance appraisal, and stress counselling. Of the 80 who replied, a quarter had received no careers guidance and a quarter no feedback about their work performance. Many reported having had difficulties in their post, but few had received help from senior staff or their consultant. The perceived needs for counselling were considerable. Careers counselling was thought to be essential in the preregistration year by all of the doctors and in senior house officer posts by three quarters. Nearly all would have chosen regular appraisal and nearly half wanted counselling for particular difficulties.
\end{abstract}

Doctors in the training grades clearly believed that they needed counselling, but in most cases they did not receive it.

\section{Introduction}

Counselling for doctors in the training grades has gathered pace since Achieving a Balance ${ }^{1}$ and Plan for Action $^{2}$ were published. In Trent Region, for example, the first year's trial of three pilot schemes for senior house officers has just been completed. Yet the Hospital Junior Staff Committee of the BMA has recently stated that "counselling is being devised without adequate consideration to the needs of the counselled." 3 This is unfortunate since the success of any scheme will depend in large part on its general acceptance by those concerned and on a coincidence of interests between management and junior staff.

Although reports on stress in junior doctors ${ }^{45}$ and the results of a study on career choice and progression ${ }^{6}$ have been published in Britain, there are virtually no data on current experience or the perceived needs of counselling. A further difficulty derives from the way in which the term "counselling" is used to denote several different activities and concerns: careers advice and guidance; performance appraisal; and stress counselling. The present study was carried out to discover what the experience and needs of postgraduate doctors in training are in these three activities.

\section{Methods and results}

All doctors who graduated from the University of Nottingham Medical School in June $1987(n=106)$ were sent questionnaires by post in May 1989. Returned questionnaires were coded, entered onto an ICL VME computer, and analysed using the statistical package for the social sciences (SPSS). The questionnaire, developed from published data on stress, career choice, etc, and piloted on a group of 30 senior house officers, had 77 questions on professional history since graduation; careers information, advice, and guidance; appraisal or feedback on work performance; stress encountered; and support sought. For statistical analyses $\chi^{2}$ or Fisher's test of exact probability with $\alpha=0.01$ were used.

Completed questionnaires were returned by 80 (75\%) of the 106 doctors; two uncompleted questionnaires were returned by doctors working outside the United Kingdom. Apart from two doctors all were senior house officers; 46 (57\%) were women; 48 (60\%) were based in teaching hospitals. The median age was 25, range 23-34 years. Twelve were in paediatrics, 14 in geriatrics, seven in obstetrics and gynaecology, 20 in other medical specialties, 14 in surgery, and 13 in other specialties such as psychiatry.

\section{CAREERS GUIDANCE}

Over half of the doctors reported receiving no careers guidance from their supervising consultant, whereas about a third had had careers guidance from their consultant, a few from the clinical tutor, and a few from others such as their father or registrar (table I). Only 28 doctors had seen the annual figures from the Department of Health on staffing prospects in the NHS. ${ }^{7}$ Nearly all of the 62 doctors who had received advice or guidance had found it useful. Over a third of all the doctors thought their consultant should provide careers guidance and a third the clinical tutor, but two thirds preferred a trained careers counsellor (table I).

TABLE I-Previous and preferred sources of careers advice and guidance. (Some doctors selected more than one source)

\begin{tabular}{lcc}
\hline Source & $\begin{array}{c}\% \text { (No) who } \\
\text { received guidance } \\
\text { from source }\end{array}$ & $\begin{array}{c}\%(\text { No) who } \\
\text { preferred guidance } \\
\text { from source }\end{array}$ \\
\hline Supervising consultant & $37(30)$ & $40(32)$ \\
Previous consultant & $19(15)$ & - \\
Clinical tutor & $10(8)$ & $39(31)$ \\
College tutor & $1(1)$ & $13(10)$ \\
Postgraduate dean & $0(0)$ & $11(9)$ \\
Trained careers counsellor & - & $66(53)$ \\
Other & $25(20)$ & $0(0)$ \\
None & $22(18)$ & $0(0)$ \\
\hline
\end{tabular}

Seventy seven doctors thought careers guidance was necessary in the middle of the preregistration year and 61 again in the middle of senior house officer appointments, suggesting a median of 30 minutes for each session. They wanted advice on $(i)$ balancing different variables in job choice (for example, hours, preference, location, opportunities for part time work); (ii) the implications of a break in normal career structure (such as working abroad, having a family); (iii) what experience and which posts would be most valuable or useful in their career; (iv) the long term prospects and options in different specialties (for example, minor, non-clinical). Advice about part time work, taking breaks to have children, and partner's job or career were the concern of many of the women and two of the men; the other concerns were common to both men and women.
NG7 2UH

Paul Garrud, DPHIL, lecturer

BrMed f 1990;300:445-7 
PERFORMANCE APPRAISAL

About three quarters of the senior house officers reported that they had had no formal appraisal or feedback from their supervising consultant: a third of these had had no feedback. For the remainder feedback varied from: "I was told I was the best houseman they'd ever had" through "useful sessions, usually in the pub" to "no feedback except the look on his face when asked for a reference" (table II).

TABLE II - Type of appraisal or feedback doctors received and their suggestions of what they wanted

\begin{tabular}{lr}
\hline & $\%(\mathrm{No})$ \\
\hline \multicolumn{1}{c}{ Feedback received } \\
Formal appraisal & \\
Adverse comments only & $23(18)$ \\
Informal, such as non-specific praise & $10(8)$ \\
Through reference & $23(18)$ \\
Word of mouth from registrar or senior registrar & $9(7)$ \\
None & $10(8)$ \\
& $25(20)$ \\
Positive and negative feedback & \\
Problems of job & $84(67)$ \\
How to improve weaknesses & $56(45)$ \\
Future plans in that specialty & $56(45)$ \\
Discussion of consultant's and junior doctor's expectations & $47(38)$ \\
Relations with staff and patients & $27(22)$ \\
Aptitude and ability & $21(17)$ \\
Discuss disagreements & $20(16)$ \\
Reading and preparation for examinations & $13(10)$ \\
& $12(9)$ \\
\hline
\end{tabular}

All doctors who had had formal appraisal had found it constructive and useful, and 66 said that they would have preferred more. This may be because they received formal appraisal at the end of their appointment. When asked about having appraisal regularly 52 suggested two interviews over a six month appointment, one early on and one in the middle or towards the end.

They wished for positive as well as negative feedback (table II) and for the appraisal to be two way, with the opportunity to discuss the job and clinical decisions or policy. Only one respondent doubted that formal appraisal was necessary for everyone. There were no reliable differences between men and women, doctors from different specialties, or those from teaching and non-teaching hospitals.

\section{STRESS COUNSELLING}

A considerable number of doctors reported experiencing difficulty in their post, many saying that they would have liked support or guidance (table III). Most thought that they had the resources to deal with several common, well known difficulties such as extended periods on call and disrupted social life. Nearly everyone who had difficulty in giving bad news

TABLE III - Problems encountered and help sought

\begin{tabular}{lrr}
\hline Type of problem & $\begin{array}{c}\%(\text { No) } \\
\text { who had } \\
\text { difficulty }\end{array}$ & $\begin{array}{c}\% \text { (No) } \\
\text { who wanted } \\
\text { help }\end{array}$ \\
\hline Giving bad news to patients or relatives & $49(39)$ & $49(39)$ \\
Feelings of disillusion or cynicism & $72(58)$ & $48(38)$ \\
Errors in diagnosis & $54(43)$ & $47(37)$ \\
Errors of treatment & $44(35)$ & $41(33)$ \\
Extended periods on duty or on call & $82(66)$ & $39(31)$ \\
Interrupted sleep or rest & $82(66)$ & $30(24)$ \\
Depression & $44(35)$ & $23(18)$ \\
Responsibility for patients & $25(20)$ & $23(18)$ \\
Balancing professional and family commitments & $36(29)$ & $20(16)$ \\
Relations with nursing staff & $26(21)$ & $19(15)$ \\
Feelings of anger & $29(23)$ & $18(14)$ \\
Inadequate diet & $44(35)$ & $16(13)$ \\
Disrupted social life & $60(48)$ & $14(11)$ \\
Relations with consultant & $14(11)$ & $13(10)$ \\
Emotional withdrawal & $14(11)$ & $10(8)$ \\
Relations with senior staff & $19(15)$ & $9(7)$ \\
Getting time away from hospital & $41(33)$ & $9(7)$ \\
Relations with juniors & $23(18)$ & $9(7)$ \\
Getting to sleep & $32(26)$ & $8(6)$ \\
\hline
\end{tabular}

or with errors in diagnosis wanted some help. Only seven had received any help from senior colleagues or their consultants, but 21 said that they had help from family, friends, and other house officers. Twenty six doctors gave reasons for not approaching their consultant or senior colleagues, such as: "One is afraid of telling senior medical staff for fear of being thought as not coping." Eighteen said that they felt they had to battle on or that they would be letting everyone down if they were ill or took time off. One reported being admitted as a pacient directly from being on call. There was a strong preference for a counsellor who was independent of the doctor's firm such as a trained counsellor (28 doctors) or a designated consultant outside their firm (21), or a clinical tutor (10), or someone else (seven). A minority nominated a supervising consultant (seven) or other team members (seven).

The doctors thought that stress counselling would be needed two or three times a year. No clear differences emerged between doctors from teaching and non-teaching hospitals, but there were some differences between specialties and between men and women. A higher proportion of doctors in geriatric and anaesthetic posts reported that they had difficulty with "responsibility for patients" than the doctors in all the other specialties ( $60 \%$ cf $10 \%)$. Men doctors reported more problems with "getting away from the hospital" and "feelings of anger" than women doctors.

\section{Discussion}

The results of this survey show that senior house officers need careers guidance, performance appraisal, and stress counselling and that these needs are not met in many cases. Doctors who had received guidance, feedback, or support were positive about it, however.

There should probably be mandatory careers advice and guidance early in postgraduate training. To be of most use, more information is needed than is generally available. ${ }^{78}$ Giving careers guidance also requires information about the doctor's competence, weaknesses, and past experience, and much of this information will be available only after appraisal. Hence, introducing appraisal is important.

In several specialties and departments the work performance and progress of doctors in the training grades are now being formally assessed, but most schemes are not far advanced. The basic requirements are reliable, valid assessment methods or tools, and regular appraisal interviews. There are several examples of this in the United States ${ }^{910}$ which may provide useful models. A component identified in this study is the junior doctor's appraisal of the job. An element that seems to encourage acceptance is negotiation and agreement of the appraisal summary between the consultant and the house officer (A Mithal, personal communication).

As for stress counselling, there is a strong preference for help that is independent of the doctor's firm and concern about the potentially detrimental effects of a doctor admitting having difficulty. The evidence of the impact of counsellors outside medicine, however, suggests that while perceived independence and assured confidentiality strongly determine acceptance, in most cases clients' fears about the consequences of consultation and releasing information are easily allayed. "After discussion, clients are often willing to have information sent to their management or personnel office. In contrast to careers guidance and appraisal, there are several other practicable ways to cope with stress. The clinical undergraduate curriculum could prepare doctors better in some aspectsfor example, giving bad news. A study has recently started in which house officers are taught techniques 
of stress management (W D Johnson, personal communication)..$^{12}$

The costs of starting counselling schemes have been addressed elsewhere, ${ }^{3}$ but a final constituent is evaluating how they work and their impact. If the general outcome is as good as the reaction reported here by the few doctors who already have such experience, or from industry," that will be an important change in postgraduate medical training.

1 Department of Health and Social Security. Hospital medical staffing: achiezing a balance. London: DHSS, 1986

2 Department of Health and Social Security. Hospital medical staffing: achiering a balance-plan for action. London: DHSS, 1987.

3 Hunter S. Careers counselling for hospital doctors in the training grades. London: British Medical Association - Hospital Junior Staff Committee, 1989.
+ Firth-Cozens J. Emotional distress in junior house officers. Br Med $f$ 1987:295:533-6

Firth-Cozens J. Stress in medical undergraduates and house officers. Brf Hosp Med 1989;41:161-4.

6 Allen I. Doctors and their careers. London: Policy Studies Institute, 1988

7 McInnes D. Medical and dental staffing prospects in the NHS in England and Wales in 1987. Health Trends 1988;20:101-9.

8 Women in Medicine. Careers for women in medicine: planning and putfalls. Lom in Medicine. Careers for women

9 Altmaier EM, Johnson SR, Tarico VS, Laube D. An empirical specification of residency performance dimensions. Obstet Gynecol 1988;72:126-30.

10 Quattlebaum TG. Sperry JB. A computerized system for evaluation of residents and residency experiences. Am $\mathcal{F}$ Dis Child 1988;142:758-62.

11 Allinson T, Cooper CL, Reynolds P. Stress counselling in the workplace. The Psychologist 1989;2:384-8.

12 Gangster DC, Maves BT. Managing organizational stress: a field experiment. f Appl Psychol 1982;67:533-42

Accepted 15 December 1989,

\title{
HIV testing in patients with end stage renal disease
}

\author{
Andrew Stevens, Janet Little, Susan Kerr, Paula Kilbane, Ciaran Doherty
}

Department of Public

Health, Mint Wing, Centre

Building, Parkside Health

Authority, London

W2 1NY

Andrew Stevens, MFCM, senior registrar

Eastern Health and Social Services Board, Belfast

Janet Little, MFCM,

consultant in public health medicine

Susan Kerr, BSC, statistician

Paula Kilbane, FFCM,

consultant in public health

medicine

\section{Regional Department of} Nephrology, Belfast City Hospital, Belfast BT9 7 AB

Ciaran Doherty, MRCP, consultant nephrologist

Correspondence to: Dr Stevens.

Br.Med f 1990;300:447-9

\begin{abstract}
One hundred and twenty eight British and Irish nephrologists were questioned about their policy for HIV testing of patients with end stage renal failure being considered for renal replacement therapy. A total of $101(79 \%)$ replied. In the case of candidates for dialysis roughly one third of respondents tested only people they considered at risk of infection with HIV and nearly one fifth considered testing unnecessary. In the case of candidates for transplantation routine HIV testing was carried out by 68 of 100 nephrologists; 22 tested only patients "at risk" and 10 did not test. A positive HIV test result was considered by most but not all respondents $(63 / 86)$ to exclude patients from transplantation. Twenty four of 88 nephrologists considered that HIV positivity should exclude patients from haemodialysis, but only seven of 87 would exclude such patients from peritoneal dialysis. Similar attitudes pertained for patients with end stage renal failure who refused HIV testing. Testing with the patient's knowledge and consent was the policy of two thirds of nephrologists, but a patient's signature was obtained by only 24 of 88.
\end{abstract}

There should be a consensus on practice for HIV testing of patients with end stage renal failure.

\section{Introduction}

Neither the clinical usefulness nor the ethics of HIV antibody testing in hospital practice when it is not part of the admitting clinical question have been fully resolved.' Furthermore, consent for testing has become a major ethical and legal issue concerning both the BMA and the General Medical Council..-5 The principle of testing only with the patient's consent has been well established, based on the potentially grave

TABLE I-Response rates among units (at least one respondent) and nephrologists according to numbers of cases of AIDS reported in their districts ${ }^{\star}$

\begin{tabular}{|c|c|c|c|c|}
\hline & \multicolumn{2}{|c|}{ Units } & \multicolumn{2}{|c|}{ Nephrologists } \\
\hline & Total & Response & Total & Response \\
\hline \multicolumn{5}{|l|}{ Districts with: } \\
\hline High reported incidence of $A I D S(\geqslant 50$ cases $)$ & 10 & 9 & 24 & 16 \\
\hline Medium reported incidence of AIDS $(10-49$ cases & 22 & 21 & 43 & 37 \\
\hline Low reported incidence of AIDS $<10$ cases $)$ & 34 & 30 & 61 & 46 \\
\hline Unknown $\dagger$ & & & - & 2 \\
\hline Total & 66 & 60 & 128 & 101 \\
\hline
\end{tabular}

^Cumulative reports to PHLS Communicable Disease Surveillance Centre by February 1989

tRespondents not identifiable. consequences of a positive result and the equivocal benefits of available treatment. ${ }^{6}$ Even offering the test with consent requires careful counselling and always requires justification.

A setting in which conventional strategies for testing have been questioned is that of patients with end stage renal failure. ${ }^{8-11}$ In haemodialysis units treatment of HIV positive patients may require precautions similar to those evolved for hepatitis B carriers. After renal transplantation in an HIV positive patient the immunosuppressive treatment needed to prevent rejection would be likely to worsen the immunodeficiency state and accelerate the disease process. ${ }^{12}$ And in all forms of renal replacement therapy demand exceeds supply, so that a degree of rationing has been the rule. ${ }^{1314}$

We report a survey carried out to determine the attitudes of British and Irish nephrologists to HIV testing of patients with end stage renal failure and to see how these attitudes influenced the strategy for treatment.

\section{Subjects and methods}

A closed, self administered questionnaire was sent to all consultant nephrologists in the United Kingdom and Republic of Ireland identified from the European dialysis and transplantation lists and the United Kingdom Transplantation Society annual report. The questionnaire asked which patients are offered or given the HIV test, whether this is with the patient's knowledge and consent, and what effect a positive test result or refusing the test would have on the selection of the patient for renal replacement. Patients were subdivided into candidates for peritoneal dialysis, haemodialysis, and renal transplantation. Nephrologists were classified according to whether the district they worked in had a high, medium, or low reported incidence of AIDS, defined as more than 50 cases, 10-49 cases, or fewer than 10 cases of AIDS reported to the Public Health Laboratory Service Communicable Disease Surveillance Centre by February 1989.

\section{Results}

One hundred and twenty eight nephrologists in 66 units were contacted, of whom $101(79 \%)$ in 60 units replied (table I). The response rate among nephrologists was higher in districts beginning to encounter AIDS than in districts with a high reported incidence of AIDS and districts in which reported cases were still 